\title{
Microplasma thruster for ultra-small satellites: Plasma chemical and aerodynamical aspects*
}

\author{
Yoshinori Takao, Takeshi Takahashi, Koji Eriguchi, and Kouichi Ono ${ }^{\ddagger}$ \\ Department of Aeronautics and Astronautics, Graduate School of Engineering, \\ Kyoto University, Yoshida-Honmachi, Sakyo-ku, Kyoto 606-8501, Japan
}

\begin{abstract}
A microplasma thruster has been developed of electrothermal type using azimuthally symmetric microwave-excited microplasmas. The microplasma source was $\sim 2 \mathrm{~mm}$ in diameter and $\sim 10 \mathrm{~mm}$ long, being operated at around atmospheric pressures; the micronozzle was a converging-diverging type, having a throat $\sim 0.2 \mathrm{~mm}$ in diameter and $\sim 1 \mathrm{~mm}$ long. Numerical and experimental results with $\mathrm{Ar}$ as a working gas demonstrated that this miniature electrothermal thruster gives a thrust of $>1 \mathrm{mN}$, a specific impulse of $\sim 100 \mathrm{~s}$, and a thrust efficiency of $\sim 10 \%$ at a microwave power of $<10 \mathrm{~W}$, making it applicable to attitudecontrol and station-keeping maneuver for a microspacecraft of $<10 \mathrm{~kg}$.
\end{abstract}

Keywords: plasma thrusters; electric propulsion; micropropulsion; microthrusters; microplasma; microdischarge; surface wave-excited plasma; micronozzle flow; microplasma jets; nano- and pico-satellites.

\section{INTRODUCTION}

Small or microspacecraft have recently attracted increasing attention in space technology, to reduce the overall mission costs and greatly increase the launch rates [1,2]. Reducing the scale of spacecraft decreases the mission costs, and simplifying the structure leads to shorter development periods. To realize microspacecraft of $<10 \mathrm{~kg}$ (or nano-/pico-satellites), their components have to be miniaturized drastically, including the propulsion system for station-keeping (requiring a thrust of $\sim \mathrm{mN}$ ) and for attitude control $(\sim \mu \mathrm{N})$. Various microthrusters have been proposed for these applications [2-6], including microelectric propulsion systems or microplasma/ion thrusters [7-17] as shown in Table 1, most of which are the applications of microplasmas or microdischarges on which extensive work has recently been done. However, none of the microthrusters have been well established until now.

We have developed a microplasma thruster of electrothermal type using azimuthally symmetric microwave-excited microplasmas [18-22], consisting of a microplasma source and a micronozzle as shown in Fig. 1. The microplasma source is made of a dielectric chamber $\sim 2 \mathrm{~mm}$ in inner diameter and $\sim 10 \mathrm{~mm}$ long covered with a metal grounded, having a metal rod antenna on axis covered with a dielectric envelope, which produces high-temperature plasmas at around atmospheric pressures. Note that the present configuration of microwave plasma source was originally developed for plasma material processing [23-26], establishing discharges relatively easily over a wide pressure range by surface waves excited around the dielectric envelope of the antenna on axis. The micronozzle concerned is a

\footnotetext{
*Paper based on a presentation at the $18^{\text {th }}$ International Symposium on Plasma Chemistry (ISPC-18), 26-31 August 2007, Kyoto, Japan. Other presentations are published in this issue, pp. 1883-2023.

¥Corresponding author: E-mail: ono@kuaero.kyoto-u.ac.jp
} 
converging-diverging one $\sim 1 \mathrm{~mm}$ in length, having a throat $\sim 0.2 \mathrm{~mm}$ in diameter, which converts high thermal energy of plasmas into directional kinetic energy of supersonic plasma flows to obtain the thrust required. The microwave power employed would be limited to $<10 \mathrm{~W}$, taking into account the electric power generated by solar cell panels installed on the microspacecraft concerned.

Table 1 Microelectric propulsion scheme.

\begin{tabular}{|c|c|c|c|}
\hline Propellant & $\begin{array}{c}\text { Electrothermal } \\
\text { (or aerodynamic) } \\
\text { acceleration }\end{array}$ & $\begin{array}{l}\text { Electromagnetic } \\
\text { acceleration }\end{array}$ & $\begin{array}{l}\text { Electrostatic } \\
\text { acceleration }\end{array}$ \\
\hline Gas & $\begin{array}{l}\text { •DC microarcjet thruster [7] } \\
\text {-DC microplasma thruster } \\
\text { (MPD) [8] }\end{array}$ & & $\begin{array}{l}\text {-Micro hall thruster [9] } \\
\text {-Micro ion thruster [10] } \\
\text {-Ferroelectric plasma } \\
\text { thruster (FEPT) [11] } \\
\text {-Dielectric capillary } \\
\text { discharge acceleration [12] }\end{array}$ \\
\hline Liquid & & & $\begin{array}{l}\text { - Field emission electric } \\
\text { propulsion (FEEP) [13] } \\
\text { •Colloid thruster [14] }\end{array}$ \\
\hline Solid & $\begin{array}{l}\cdot \text { Vacuum arc microthruster } \\
(\mathrm{VA} \mu \mathrm{T})[15] \\
\text {-Microlaser-ablation plasma } \\
\text { thruster }(\mu \text {-LPT) }[16]\end{array}$ & $\begin{array}{l}\cdot \text { Micropulsed plasma } \\
\text { thruster }(\mu \text {-PPT) [17] }\end{array}$ & \\
\hline
\end{tabular}

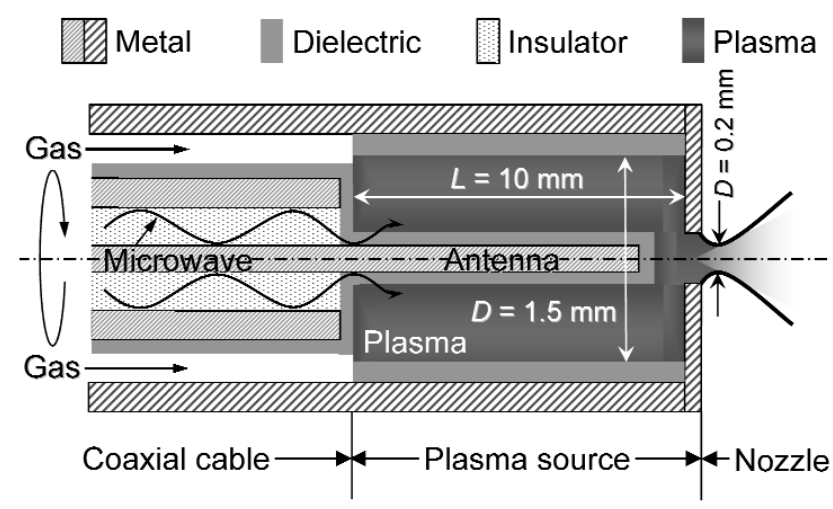

Fig. 1 Schematic of the microplasma thruster using azimuthally symmetric microwave-excited microplasmas.

Since the plasmas are excited by surface waves, the major feature of our system is that microwaves penetrate into the plasma chamber along the plasma-dielectric interfaces even in the overdense mode, and so the electron heating occurs in a thin (a few millimeters deep or less) skin-depth layer; that is, most of the power is absorbed near the interfaces. Such mechanism of the power deposition is a great advantage to generate plasmas in a limited space without magnetic-field confinement. These features would contribute to a simple structure and long-time operation, compared with other conventional microthrusters, because the present thruster requires no electrodes, neutralizers, and magnets. This paper presents numerical and experimental studies of the microplasma thruster presently developed, with emphasis being placed on prominent plasma chemical and aerodynamical aspects of the microwave-excited microplasma and micronozzle flow. 


\section{MICROTHRUSTERS}

In general, rocket propulsion or thruster systems are classified according to the type of energy source (chemical, electric, nuclear), the type of propellant (solid, liquid, gas), and the method of producing thrust (electrothermal, electromagnetic, electrostatic) [27,28]. Propulsion for spacecraft in orbit has so far been provided by chemical rockets using liquid propellants; in practice, liquid-propellant rockets are versatile as compared to solid-propellant ones, being used for station-keeping through repeatedly turning them on and off. Cold-gas thrusters are more versatile for station-keeping and also for attitude control because of their simple systems, but give limited performances owing to low thrust and low specific impulse. The electric propulsion has recently been used for station-keeping in orbit, although it has a disadvantage of heavy and insufficient power sources; in practice, the thrust of electric propulsion is low, but the specific impulse is so high that the electric propulsion can give an increase in the spacecraft velocity through applying the low thrust and thus a small acceleration for a long time. It is noted here that the thrust is the force produced by a rocket propulsion system acting upon a spacecraft, being given by the sum of the momentum and pressure thrusts: $F_{\mathrm{t}}=\dot{m} u+\left(p-p_{\mathrm{e}}\right) A$, where $\dot{m}$ is the mass flow rate of propellant, $u$ is its exhaust velocity at the nozzle exit, $p$ is the exhaust propellant pressure thereat, $p_{\mathrm{e}}$ is the ambient pressure around the spacecraft, and $A$ is the cross-sectional area at the nozzle exit. On the other hand, the specific impulse is the thrust divided by weight flow rate of propellant or a thrust per unit weight flow rate: $I_{\mathrm{sp}}=F_{\mathrm{t}} / \dot{m} g$, where $g$ is the acceleration of gravity at sea level. The specific impulse $I_{\mathrm{sp}}$ is a measure of the efficiency of propellant consumption: the higher the specific impulse, the less propellant is required to gain a given amount of momentum. In general, propulsion systems with high specific impulse produce low thrusts.

For micropropulsion or microthrusters [3], the specific impulse is an especially important performance parameter, owing to a limited mass or size of small or microspacecraft (hopefully requiring a specific impulse of $>500 \mathrm{~s}$ ). Thus, microelectric propulsion systems are strongly required for microspacecraft in their novel as well as conventional forms, although small liquid chemical rockets and coldgas thrusters are considered in their conventional forms. Figure 2 shows the approximate regions of application of different microelectric propulsion systems (as listed in Table 1) in terms of thrust and specific impulse, together with those of microchemical rockets and cold-gas thrusters. The situation is similar to that of conventional large propulsion systems. There are three general categories of electric propulsion system according to the method of producing thrust [27,28]: electrothermal, electromagnetic, and electrostatic. Electrothermal propulsion resembles chemical rocket and gas thruster sys-

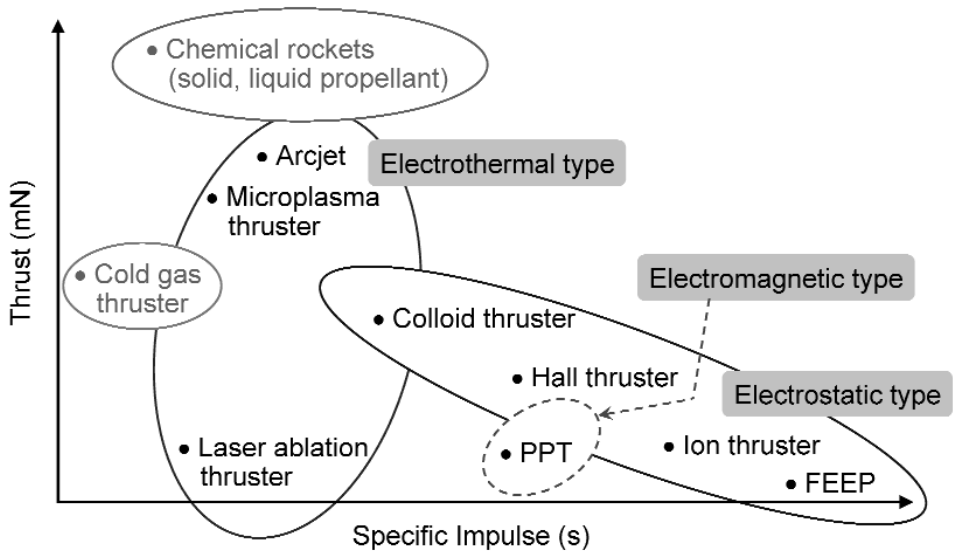

Fig. 2 Overview of the approximate regions of application of different microelectric propulsion systems in terms of thrust and specific impulse, together with those of microchemical rockets and cold-gas thrusters. The situation is similar to that of conventional large propulsion systems. 
tems, where the propellant is heated electrically, and the hot gas is then thermodynamically or aerodynamically expanded and accelerated to supersonic flow through an exhaust nozzle. Electromagnetic propulsion accelerates current-carrying plasmas by externally applied or self-generated magnetic fields. Electrostatic propulsion accelerates ions by electrostatic potentials externally applied or self-generated. Among these three, the electrothermal type would significantly contribute to a simple structure and long-time operation of microelectric propulsion systems, because the electrothermal type requires no electrodes, neutralizers, and magnets.

\section{NUMERICAL ANALYSIS}

The numerical model consisted of an electromagnetic module for microwave propagation in interacting with plasmas and a fluid module for plasma flows with two (electron and heavy particle) temperatures $[18,22]$. The former employed the finite difference time-domain (FDTD) approximation, being applied to the plasma source region, to analyze the microwave power absorbed in the plasma. The latter employed two-temperature fluid equations, being applied to both the source and nozzle regions, to analyze the plasma and nozzle flow characteristics with strong plasma-wall interactions in a limited space. In practice, the microplasma source has a relatively large surface area-to-volume ratio as compared to conventional large plasma sources, and so plasma loss is relatively large at microplasma source chamber walls. The analysis of the nozzle flow finally gave the thrust performance achieved. The working gas of interest in this study was Ar, and the numerical analysis relied on the cylindrical coordinate system assuming that (i) the plasma is quasi-neutral; (ii) the atomic processes in the gas phase are electron impact ionization and the reverse process or three-body recombination; (iii) the temperature of electrons is different from that of heavy particles (ions and neutrals); (iv) the microwave energy is absorbed by plasma electrons, which in turn, are transferred to heavy particles through elastic collisions; (v) the gas and plasma flow is neglected in the plasma source region; and (vi) the nozzle flow is laminar and the mean flow velocity is the same for all species (electrons and heavy particles). It is further noted that in the present fluid model/module, the convective flow was neglected in the source region as mentioned above, or the momentum balance was replaced by the drift-diffusion approximation therein, where the electrostatic field occurs in the electron continuity and energy balance equations owing to ambipolar diffusion of ions and electrons; of course, the direct current (DC) is zero in the system, and the mobility is set equal to zero for neutrals $[22,26]$. This approximation reproduced the plasma characteristics in the source region within an accuracy of $\pm 10 \%$, because the diffusion (caused by density gradients) was dominated in the microplasma source region having a limited space surrounded by walls.

Figure 3 shows the spatial distribution of the electron density $n_{\mathrm{e}}$, electron temperature $T_{\mathrm{e}}$, heavy particle temperature $T_{\mathrm{h}}$, and absorbed power density $Q_{\mathrm{abs}}$ in the microplasma source, calculated for an input power $P_{\text {in }}=10 \mathrm{~W}$ of $f=4 \mathrm{GHz}$ microwaves, Ar pressure of $P_{0}=20 \mathrm{kPa}$, and quartz chamber and envelope $\left(\varepsilon_{\mathrm{d}}=3.8\right)$ with a wall temperature $T_{\mathrm{w}}=500 \mathrm{~K}$ (isothermal walls) [18,22]. The absorbed power calculated in the plasma was $P_{\mathrm{abs}}=5.0 \mathrm{~W}$ in total, corresponding to the average power density $\bar{Q}_{\mathrm{abs}}=$ $6.3 \times 10^{2} \mathrm{~W} / \mathrm{cm}^{3}$ ). The plasma density $n_{\mathrm{e}}$ exhibits its maximum near the end of the dielectric envelope of the antenna $\left(n_{\mathrm{e}} \approx 2 \times 10^{14} \mathrm{~cm}^{-3}\right)$, being consistent with the distribution of the electron temperature $T_{\mathrm{e}}$ and absorbed power density $Q_{\mathrm{abs}}$. On the other hand, the heavy particle temperature $T_{\mathrm{h}}$ exhibits its maximum in a space between the end of the dielectric envelope and the end wall of the dielectric plasma source chamber $\left(T_{\mathrm{h}} \approx 1000 \mathrm{~K}\right)$, where the nozzle is located to achieve the aerodynamic acceleration of high-temperature plasmas. Such distribution of the gas temperature is preferred for a thruster of electrothermal type using a Laval nozzle (or a converging-diverging nozzle). Numerical results also indicated that the microwave power absorbed increases with increasing microwave frequency $f$ and relative permittivity $\varepsilon_{\mathrm{d}}$ of dielectrics; in practice, the surface waves tend to be established in the microplasma source at high frequencies and permittivities. 
(a) Electron density $n_{\mathrm{e}}\left(10^{12} \mathrm{~cm}^{-3}\right)$

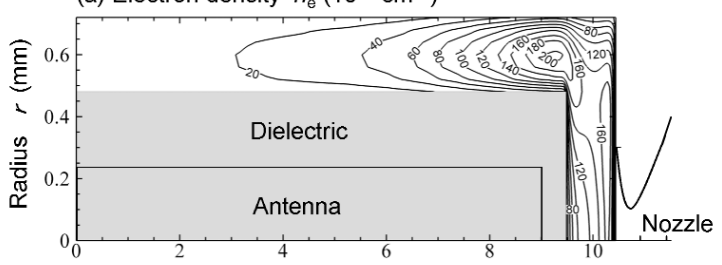

(c) Heavy particle temperature $T_{\mathrm{h}}(\mathrm{K})$

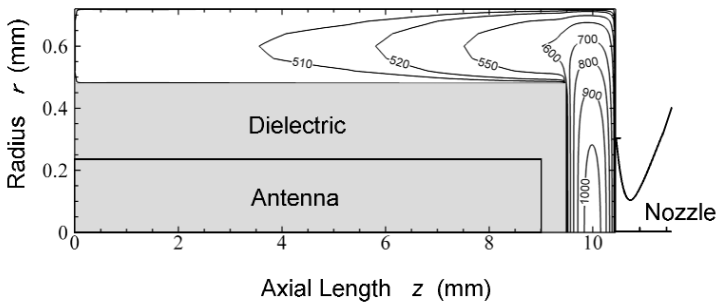

(b) Electron temperature $T_{\mathrm{e}}\left(10^{3} \mathrm{~K}\right)$

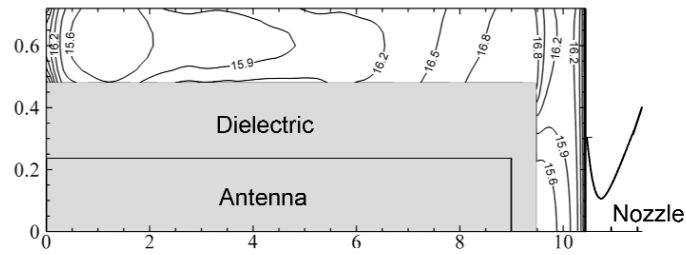

(d) Absorbed power density $Q_{\text {abs }}\left(\mathrm{W} / \mathrm{cm}^{3}\right)$

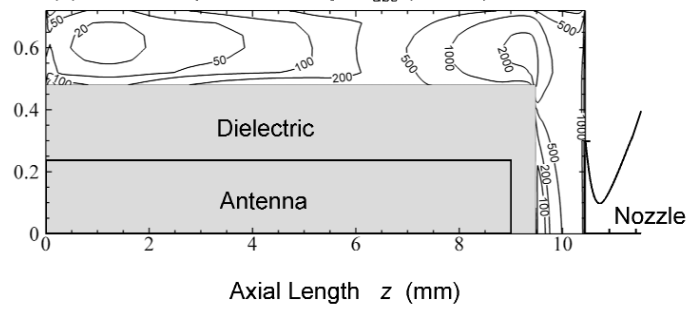

Fig. 3 Distribution of the (a) electron density $n_{\mathrm{e}}$, (b) electron temperature $T_{\mathrm{e}}$, (c) heavy particle temperature $T_{\mathrm{h}}$, and (d) absorbed power density $Q_{\text {abs }}$ in the microplasma source, calculated at an Ar pressure of $P_{0}=20 \mathrm{kPa}$. Here, the diameter and length of the antenna are $d_{\text {an }}=0.48 \mathrm{~mm}$ and $L_{\text {an }}=9 \mathrm{~mm}$, respectively; the outer diameter and length of the dielectric envelope $\left(\varepsilon_{\mathrm{d}}=3.8\right)$ around the antenna are $d_{\mathrm{di}}=0.96 \mathrm{~mm}$ and $L_{\mathrm{di}}=9.5 \mathrm{~mm}$, respectively; the inner diameter, outer diameter, and length of the dielectric chamber $\left(\varepsilon_{\mathrm{d}}=3.8\right)$ are $d_{\text {inn }}=1.44 \mathrm{~mm}, d_{\text {out }}=3.0 \mathrm{~mm}$, and $L=10.5 \mathrm{~mm}$, respectively. Moreover, the microwave input power was taken to be $P_{\text {in }}=10 \mathrm{~W}(f=4 \mathrm{GHz})$, and the power absorbed in the plasma was $P_{\text {abs }}=5.0 \mathrm{~W}$.

Figure 4 shows the distribution of the Mach number $M_{a}$ and flow velocity $U$ in the micronozzle for different absorbed powers $P_{\text {abs }}=1.3$ and $5.0 \mathrm{~W}$ in the plasma source region, calculated with an Ar mass flow rate of $\dot{m}=2.0 \mathrm{mg} / \mathrm{s}(66 \mathrm{sccm})$ assuming non-slip conditions at the nozzle wall $[18,22]$. The other conditions are the same as in Fig. 3. It should be noted here that in case of high $P_{\text {abs }}$, the micronozzle flow is heavily affected by viscous dissipation in boundary layers owing to the high temperature of heavy particles, resulting in the deceleration of supersonic flows or the decrease of Mach numbers and flow velocities in the diverging section of the nozzle. In practice, in the micronozzle flow, the thickness of boundary layers is comparable to the characteristic radius of the nozzle cross-section.
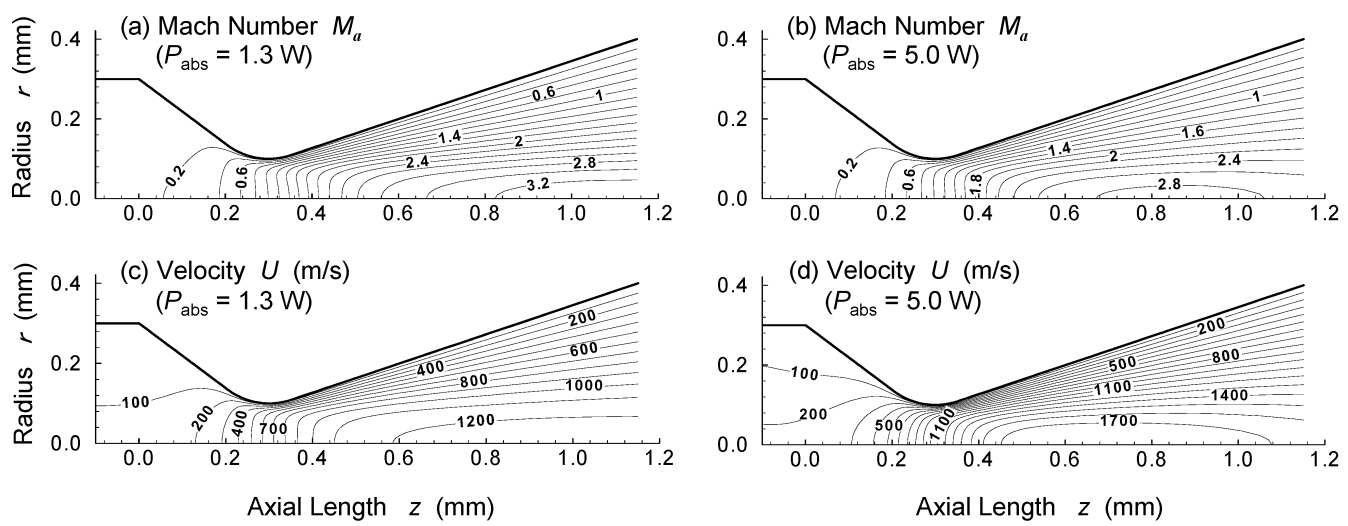

Fig. 4 Distribution of the Mach number $M_{a}$ and flow velocity $U$ in the micronozzle for different absorbed powers $P_{\text {abs }}=1.3$ and $5.0 \mathrm{~W}$ in the plasma source region, calculated with an Ar mass flow rate of $\dot{m}=2.0 \mathrm{mg} / \mathrm{s}(66 \mathrm{sccm})$. The other conditions are the same as in Fig. 3. Here, the nozzle shown has an inlet, throat, and exit diameter of $d_{\text {in }}=0.6 \mathrm{~mm}, d_{\mathrm{th}}=0.2 \mathrm{~mm}$, and $d_{\mathrm{ex}}=0.8 \mathrm{~mm}$, respectively, with a diverging angle of $\theta=20^{\circ}$. 
The thrust performance was evaluated by calculating the thrust or reaction force to propel spacecraft and the specific impulse or fuel efficiency of thruster, which are expressed as $[18,20,21]$

$$
F_{\mathrm{t}}=2 \pi \int_{0}^{r_{\mathrm{ex}}}\left(\rho u^{2}+p\right) r d r, \quad I_{\mathrm{sp}}=F_{\mathrm{t}}\left(g 2 \pi \int_{0}^{r_{\mathrm{ex}}} \rho u r d r\right)^{-1}=F_{\mathrm{t}} /(\dot{m} g)
$$

respectively. Here, $r_{\mathrm{ex}}$ is the nozzle radius at the exit, $\rho$ is the mass density, $u$ is the exhaust velocity in the axial direction, $p$ is the pressure, and $g$ is the gravitational constant. In principle, an increase in thrust $F_{\mathrm{t}}$ requires an increase in velocity $u$ at the nozzle exit, which in turn requires an increase in gas/plasma temperature $T_{\mathrm{h}}$ in the plasma source region heated by microwaves. It is noted that the thrust $F_{\mathrm{t}}$ consists of the momentum and pressure thrusts, as mentioned earlier. The pressure thrust is usually neglected owing to its less contribution to the total thrust; however, reducing the size of the nozzle results in under-expanded gas/plasma flows inside the nozzle, as mentioned above, so that the pressure thrust has also to be taken into account in microthrusters of electrothermal type. The present analysis gave a thrust of $F_{\mathrm{t}} \approx 2.5-3.5 \mathrm{mN}$ and a specific impulse of $I_{\mathrm{sp}} \approx 130-180 \mathrm{~s}$ [18].

\section{EXPERIMENT}

Figure 5a shows a schematic of the experimental set-up [20,21]. The microplasma source was made of a quartz tube $10 \mathrm{~mm}$ long, $1.5 \mathrm{~mm}$ in inner diameter, and $3.0 \mathrm{~mm}$ in outer diameter, being located in a vacuum chamber pumped down. The center conductor of a semi-rigid coaxial cable, protruding $10 \mathrm{~mm}$ beyond the insulator and outer conductor, was covered with a dielectric envelope, being inserted in the source chamber as a microwave antenna. The dielectric envelope was $10 \mathrm{~mm}$ long, $0.5 \mathrm{~mm}$ in inner diameter, and $1.0 \mathrm{~mm}$ in outer diameter, where three types of dielectrics, quartz $\left(\varepsilon_{\mathrm{d}} \approx 3.8\right)$, mullite $\left(\varepsilon_{\mathrm{d}} \approx 6\right)$, and zirconia $\left(\varepsilon_{\mathrm{d}} \approx 12-25\right)$, were employed to investigate the dependence on the dielectric constant. Both the plasma source chamber and antenna were inserted into a stainless-steel housing to cover the microplasma source with a metal grounded, where an annular spacing was retained for feeding the fuel gas through it.

Microwave signals of $f=2$ and $4 \mathrm{GHz}$ were amplified through a four-stage semiconductor amplifier to powers of nominally $P_{\text {in }}<10 \mathrm{~W}$, and then fed through the semi-rigid coaxial cable into the microplasma source. The working gas was Ar in this study, being supplied through a mass flow controller; in some cases, a small amount of $\mathrm{N}_{2}$ and $\mathrm{H}_{2}$ was added for plasma diagnostics. The feed gas pressure $P_{0}$ in the plasma source was measured by the pressure gauge set upstream of the source chamber. Here, the plasma was generated with the help of an igniter, and the reflection of microwaves was suppressed by adjusting the length of cable and antenna.

Figure $5 \mathrm{~b}$ shows a microscope image of the micronozzle fabricated in a 1-mm-thick quartz plate using a micromachining process with a diamond drill. The nozzle shown has an inlet, throat, and exit diameter of $0.6,0.2$, and $0.8 \mathrm{~mm}$, respectively, being similar to the nozzle configuration of Fig. 4. The micronozzle was attached to one end of the microplasma source chamber by using ceramic paste, as shown in Fig. 5a. Plasma discharges gave an elongated plume of supersonic plasma jet downstream of the nozzle exit into vacuum, as shown in Figs. $5 \mathrm{c}$ and d; the length of the plasma jet plume was observed to increase with increasing microwave input power $P_{\text {in }}$ and gas flow rate. In addition, the jet plume was observed to have a system of shocks therein (barrel shock at the sides and Mach disk shock normal to the centerline), indicating a supersonic free-jet expansion through an orifice or nozzle into vacuum. 


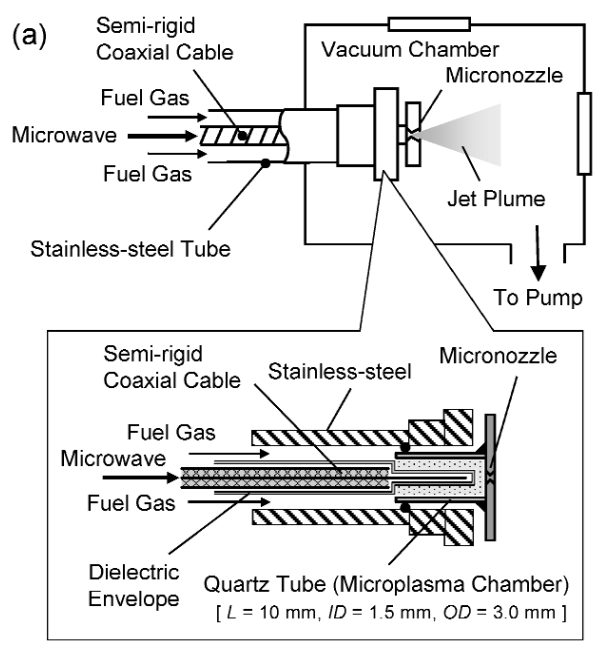

(b)

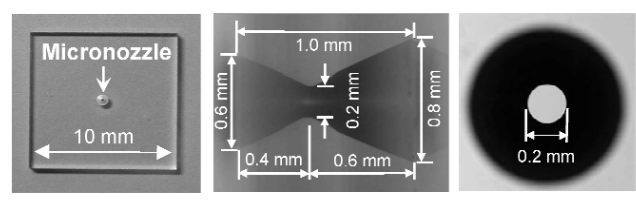

(c)

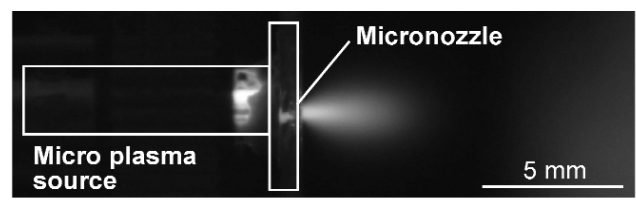

(d)

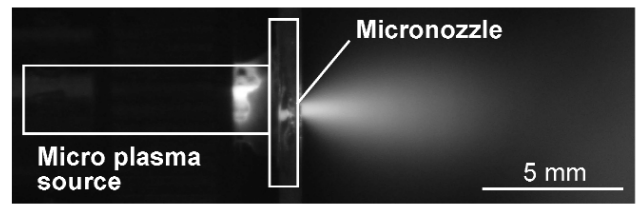

Fig. 5 (a) Experimental set-up with an enlarged view of the microwave-excited microplasma source. Also shown is (b) a microscope image of the micronozzle fabricated, together with photograph images of supersonic Ar plasma jet plume through the nozzle into vacuum at $P_{\text {in }}=(\mathrm{c}) 3 \mathrm{~W}$ and (d) $5 \mathrm{~W}$ ( $f=4 \mathrm{GHz}, \varepsilon_{\mathrm{d}} \approx 3.8$, Ar $50 \mathrm{sccm}, P_{0}=$ $50 \mathrm{kPa})$.

\section{PLASMA CHARACTERISTICS}

To characterize the microplasma concerned, the optical emission from the plasma was observed in the side-view direction through small holes of the stainless-steel housing around the end of the antenna or dielectric envelop, and the Langmuir probe was located in the plasma jet plume downstream of the nozzle exit [20-22]. A 50-cm focal length spectrograph/monochromator was employed in these experiments, having a grating of 2400 lines/mm, CCD detector, and photomultiplier; the spectral resolution, determined using a low-pressure Ar discharge lamp, was about $0.025 \mathrm{~nm}$ with an entrance slit width of $5 \mu \mathrm{m}$. The experiments exhibited the emission intensity and electron density increasing with increasing microwave power $\left(P_{\text {in }}=1-10 \mathrm{~W}\right)$, frequency $(f=2,4 \mathrm{GHz})$, and dielectric constant $\left(\varepsilon_{\mathrm{d}} \approx 3.8,6,12-25\right)$ of the envelope.

Figure 6 shows the electron density $n_{\mathrm{e}}$ and rotational temperature $T_{\text {rot }}$ measured as a function of microwave power $P_{\text {in }}$ and Ar gas flow rate, together with a numerical fit of the optical emission spectrum profile measured. Here, the plasma electron density was that measured by adding a small amount of $\mathrm{H}_{2}$ and analyzing the Stark broadening of the $\mathrm{H}$ Balmer- $\beta$ spectral line at $480.6 \mathrm{~nm}$ as in Fig. 6a. In practice, the $\mathrm{H}_{\beta}$ line broadening is appreciated to consist of the instrumentation $\Delta \lambda_{\text {instrum }}$, Doppler $\Delta \lambda_{\text {Doppler }}$ (depending on gas temperature $T_{\mathrm{g}}$ ), pressure $\Delta \lambda_{\text {pressure }}$ (depending on $T_{\mathrm{g}}$ and $P_{0}$ ), and Stark broadening $\Delta \lambda_{\text {Stark }}$ (depending on $n_{\mathrm{e}}$ and $T_{\mathrm{e}}$ ); the former two are given by the Gaussian profile and the latter two by the Lorentzian profile, which are then approximated by the Voigt function in total with a full width at half maximum (FWHM) of $\Delta \lambda_{\mathrm{V}}$. Typically, $\Delta \lambda_{\mathrm{V}} \approx 0.06 \mathrm{~nm}, \Delta \lambda_{\text {instrum }} \approx 0.025 \mathrm{~nm}$, $\Delta \lambda_{\text {Doppler }} \approx 0.011 \mathrm{~nm}, \Delta \lambda_{\text {pressure }} \approx 0.005 \mathrm{~nm}$, and $\Delta \lambda_{\text {Stark }} \approx 0.043 \mathrm{~nm}$ gave $n_{\mathrm{e}} \approx 9.9 \times 10^{13} \mathrm{~cm}^{-3}$, assuming $T_{\mathrm{g}} \approx 1000 \mathrm{~K}$ and $P_{0} \approx 50 \mathrm{kPa}$, where we used the Stark broadening parameter of Griem [29] in the analysis of $\Delta \lambda_{\text {Stark }}$ depending on $n_{\mathrm{e}}$ and $T_{\mathrm{e}}$. It should be noted here that we have to pay attention to the accuracy of electron density determined from the Stark broadening, arising from the spectral resolution of the measurement system and also from the assumption of analysis; in practice, the present accuracy was estimated to be about $\pm 20 \%$, primarily owing to the resolution $\Delta \lambda_{\text {instrum }} \approx 0.025 \mathrm{~nm}$ of the spectrometer system employed. The electron density thus measured was in the range $n_{\mathrm{e}} \approx 7-12 \times$ $10^{13} \mathrm{~cm}^{-3}$, being consistent with the Langmuir probe measurements in the supersonic plasma free jet downstream of the nozzle $[19,20]$ and also with the results of numerical analysis as shown in Fig. 3 . 

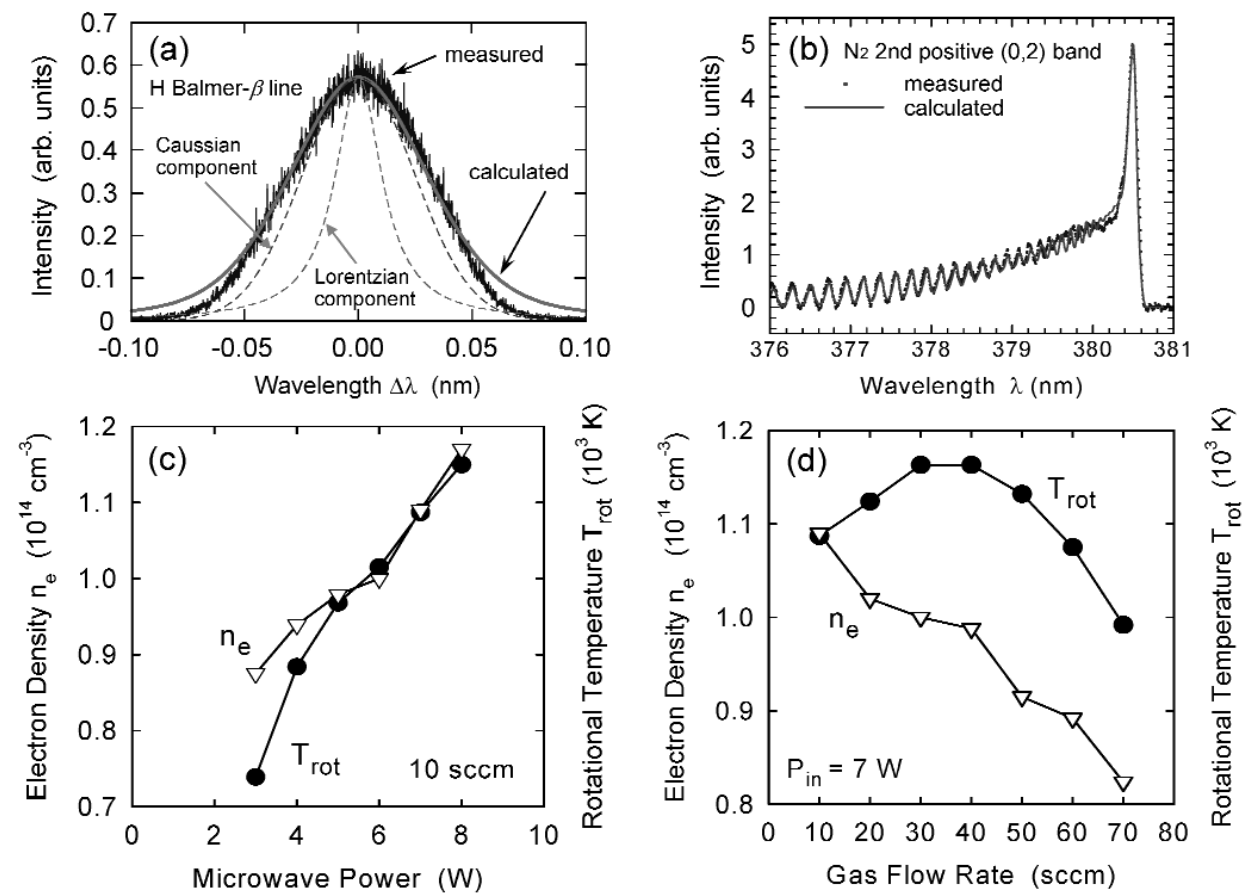

Fig. 6 (a) Optical emission spectrum profile of the $\mathrm{H}$ Balmer- $\beta$ line at $480.6 \mathrm{~nm}$, together with the fitting Voigt function curve assuming $\Delta \lambda_{\mathrm{V}}=0.06 \mathrm{~nm}$. (b) Vibronic spectrum of the $\mathrm{N}_{2} 2^{\text {nd }}$ positive $(0,2)$ band at $380.4 \mathrm{~nm}$, together with the fitting curve theoretically estimated assuming $T_{\text {rot }}=1010 \mathrm{~K}$. Also shown in (c) and (d) are the electron density $n_{\mathrm{e}}$ and rotational temperature $T_{\text {rot }}$ measured as a function of microwave input power $P_{\text {in }}$ and $\mathrm{Ar}$ gas flow rate, respectively. Here, $n_{\mathrm{e}}$ was measured from the Stark broadening of the $\mathrm{H}$ Balmer- $\beta$ line, and $T_{\text {rot }}$ from the vibronic feature of the $\mathrm{N}_{2} 2^{\text {nd }}$ positive $(0,2)$ band. The experimental conditions were the same as in Fig. 5, unless an additive gas $\left(\mathrm{H}_{2}\right.$ or $\left.\mathrm{N}_{2}\right)$ flow rate of $0.2 \mathrm{sccm}$.

The gas/rotational temperature was measured by adding a small amount of $\mathrm{N}_{2}$ and analyzing the vibronic spectrum of the $\mathrm{N}_{2} 2^{\text {nd }}$ positive $(0,2)$ band at $380.4 \mathrm{~nm}$ as in Fig. $6 \mathrm{~b}$; the temperature was in the range $T_{\mathrm{g}} \sim T_{\text {rot }} \approx 700-1200 \mathrm{~K}$, being consistent with the numerical analysis as in Fig. 3. It is noted that the plasma density $n_{\mathrm{e}}$ and gas temperature $T_{\mathrm{g}}$ increased with increasing microwave power $P_{\text {in }}$, while the behavior of $n_{\mathrm{e}}$ as a function gas flow rate was different from that of $T_{\mathrm{g}}$. Moreover, the temperature $T_{\text {rot }}$ was found to increase toward the exit of the source region where the micronozzle was equipped, and also to increase with increasing $P_{\text {in }}, f$, and $\varepsilon_{\mathrm{d}}$. It is noted that the temperature distribution presently observed, or the maximum $T_{\text {rot }}$ around the exit of the microplasma source region, is important for the microplasma thruster of electrothermal type; in effect, to achieve high thrust performance, the plasma thermal energy should be converted into directional kinetic energy of supersonic flow without any undesirable energy loss in the plasma source chamber before entering the nozzle.

\section{THRUST PERFORMANCE}

Figure 7 shows a schematic of the experimental set-up for thrust measurement, which was newly developed for microthrusters of $F_{\mathrm{t}} \leq 1 \mathrm{mN}$, consisting of a pendulum-type stand for cold-gas operation and a target-type stand for both cold-gas and plasma-discharge operations [21]. In the former, the thruster itself was hung; in the latter, a small concave target block was hung downstream of the nozzle exit with the thruster fixed tightly, and the gas/plasma plume ejected from the thruster struck a cylindrical target mounted at one end of the pendulum with some weights being at the other end for balance. 

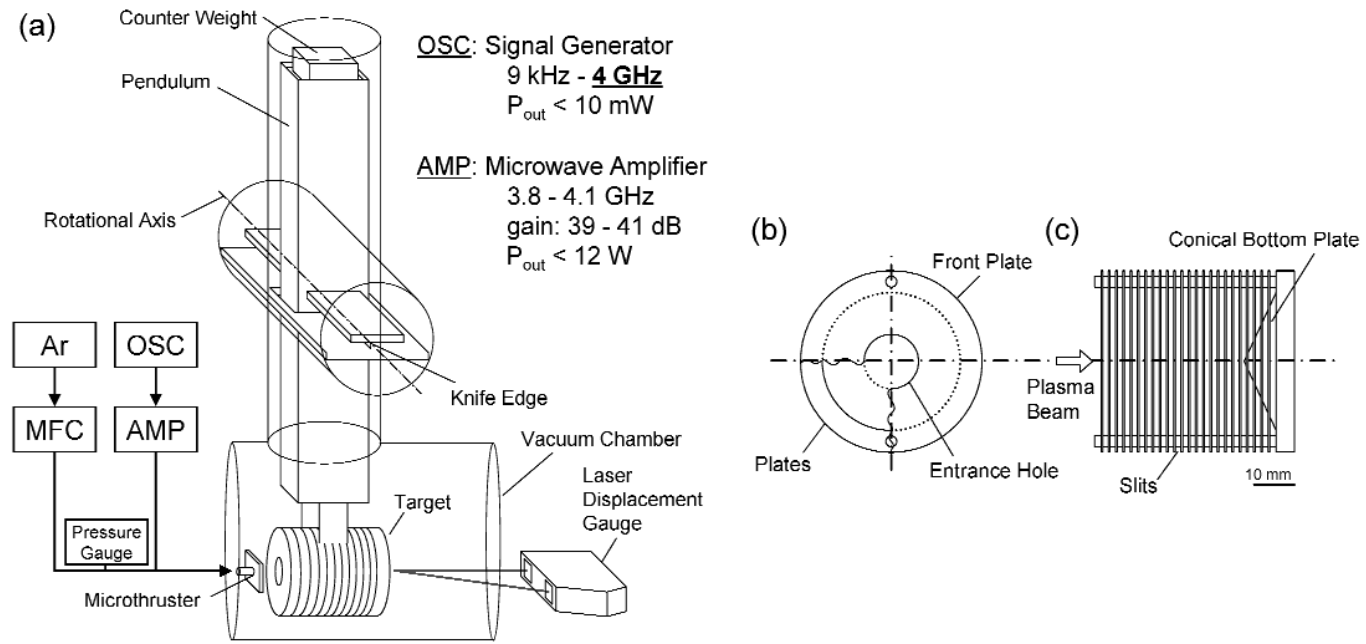

Fig. 7 (a) Schematic diagram of the experimental set-up for thrust measurement presently developed for microthrusters. Also shown are (b) front and (c) side views of the cylindrical target made of Teflon.

Here, the target employed was a small Faraday cup-like one made of Teflon, to suppress the effects of reflected particles of the jet plume that struck the target. The small displacement $(\Delta x<0.1 \mathrm{~mm})$ in operation was measured by using a laser displacement gauge.

Figure 8 shows the thrust performance [21,22] measured as a function of Ar gas flow rate for different microwave input powers, where $P_{\text {in }}=0 \mathrm{~W}$ corresponds to the cold-gas operation without plasma discharges. The measurements showed that the thrust performance was enhanced with the discharge on, and that the thrust and specific impulses were $F_{\mathrm{t}} \approx 1.4 \mathrm{mN}$ and $I_{\mathrm{sp}} \approx 80 \mathrm{~s}$, respectively, with the thrust efficiency $\eta_{\mathrm{t}} \approx 8.7 \%$ at a power of $P_{\text {in }}=6 \mathrm{~W}$ and an Ar gas flow rate of $60 \mathrm{sccm}(1.8 \mathrm{mg} / \mathrm{s})$, being consistent with the numerical analysis as shown in Fig. 4.
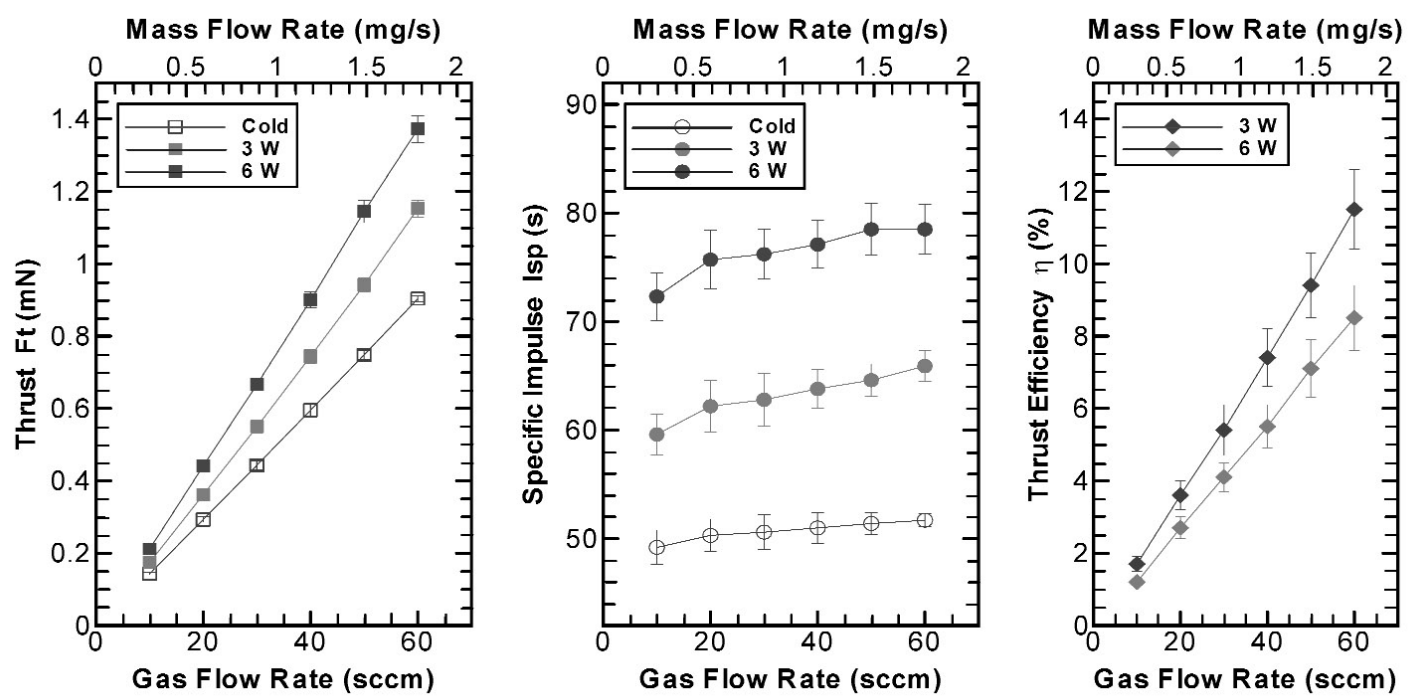

Fig. 8 Thrust performance (thrust $F_{\mathrm{t}}$, specific impulse $I_{\mathrm{sp}}$, and thrust efficiency $\eta_{\mathrm{t}}$ ) measured as a function of Ar gas flow rate for different microwave input powers $P_{\text {in }}$. Here, $P_{\text {in }}=0 \mathrm{~W}$ corresponds to the cold-gas operation without plasma discharges. The experimental conditions were the same as in Figs. 5 and 6. 


\section{CONCLUSIONS}

A microplasma thruster has been developed of electrothermal type using azimuthally symmetric microwave-excited microplasmas, consisting of a microplasma source and micronozzle. The microplasma source was made of a dielectric chamber $\sim 2 \mathrm{~mm}$ in inner diameter and $\sim 10 \mathrm{~mm}$ long covered with a metal grounded, having a metal rod antenna on axis covered with a dielectric envelope, which produced high-temperature plasmas at around atmospheric pressures. The micronozzle was a converging-diverging type (or a Laval nozzle), having a throat $\sim 0.2 \mathrm{~mm}$ in diameter, converting high thermal energy of plasmas into directional kinetic energy of supersonic plasma flows to obtain the thrust required. Numerical simulation and experiments with $\mathrm{Ar}$ as a working gas indicated that in the miroplasma source, the plasma density was typically $n_{\mathrm{e}} \approx 1 \times 10^{14} \mathrm{~cm}^{-3}$ with a gas temperature of $T_{\mathrm{g}} \approx T_{\text {rot }} \approx$ $1000 \mathrm{~K}$ at a pressure of $P_{0} \approx 50 \mathrm{kPa}$ and an input microwave power of $P_{\text {in }}<10 \mathrm{~W}$; moreover, this miniature electrothermal thruster was demonstrated to give a thrust of $>1 \mathrm{mN}$ and a specific impulse of $\sim 100 \mathrm{~s}$ at a microwave power of $<10 \mathrm{~W}$, being applicable to attitude-control and station-keeping maneuver for microspacecraft of $<10 \mathrm{~kg}$.

\section{ACKNOWLEDGMENTS}

This work was supported in part by a Grant-in-Aid for Scientific Research from the Japan Society for the Promotion of Science, and in part by the $21^{\text {st }}$ Century Center of Excellence (COE) program of the Ministry of Education, Culture, Sports, Science and Technology.

\section{REFERENCES}

1. E. Y. Robinson, H. Helvajian, S. W. Janson. Aerospace America Oct. 38 (1996).

2. H. Helvajian (Ed.). Microengineering Aerospace Systems, AIAA, Reston, VA (1999).

3. M. M. Micci, A. D. Ketsdever (Eds.). Micropropulsion for Small Spacecraft, AIAA, Reston, VA (2000).

4. J. R. Wilson. Aerospace America, Feb. 34 (2003).

5. M. Tajmar. Advanced Space Propulsion Systems, Springer, Vienna (2004).

6. R. Osiander, M. A. G. Darrin, J. L. Champion (Eds.), J. Schein. In MEMS and Microstructures in Aerospace Applications, Chap. 11, pp. 229-267, CRC Press, Boca Raton, FL (2005).

7. H. Horisaka, K. Onodera, T. Noda, I. Kimura. Vacuum 80, 1244 (2006).

8. P. S. Kothnur, L. L. Raja. J. Appl. Phys. 97, 043305 (2005).

9. T. Ito, M. A. Cappelli. Appl. Phys. Lett. 89, 061501 (2006).

10. H. Kataharada, Y. Takao, N. Yamamoto, H. Ijiri, H. Nakashima. Thin Solid Films 506-507, 605 (2006).

11. M. A. Kemp, S. D. Kovaleski. J. Appl. Phys. 100, 113306 (2006).

12. A. Dunaevsky, Y. Raitses, N. J. Fisch. Appl. Phys. Lett. 88, 251502 (2006).

13. M. Tajmar, A. Genovese, W. Steiger. J. Propul. Power 20, 211 (2004).

14. S. Castro, R. Bocanegra. Appl. Phys. Lett. 88, 123105 (2006).

15. J. Schein, N. Qi, R. Binder, M. Krishnan, J. K. Ziemer, J. E. Polk, A. Anders. Rev. Sci. Instrum. 73, 925 (2002).

16. M. Keidar, I. D. Boyd, J. Luke, C. Phipps. J. Appl. Phys. 96, 49 (2004).

17. E. L. Antonsen, R. L. Burton, G. A. Reed, G. G. Spanjers. Rev. Sci. Instrum. 77, 103107 (2006).

18. Y. Takao, K. Ono. Plasma Sources Sci. Technol. 15, 211 (2006).

19. Y. Takao, K. Ono, K. Takahashi, Y. Setsuhara. Thin Solid Films 506-507, 592 (2006).

20. Y. Takao, K. Ono, K. Takahashi, K. Eriguchi. Jpn. J. Appl. Phys. 45, 8235 (2006).

21. Y. Takao, K. Eriguchi, K. Ono. J. Appl. Phys. 101, 123307 (2007). 
22. T. Takahashi, Y. Takao, K. Eriguchi, K. Ono. In Proc. of the $30^{\text {th }}$ International Electric Propulsion Conference, Florence, Italy, September 2007, IEPC-2007-29.

23. M. Tuda, K. Ono. J. Vac. Sci. Technol., A 16, 2832 (1998).

24. M. Tuda, K. Ono, H. Ootera, M. Tsuchihashi, M. Hanazaki, T. Komerura. J. Vac. Sci. Technol., A 18, 840 (2000).

25. H. Kousaka, K. Ono. Jpn. J. Appl. Phys. 41, 2199 (2002).

26. H. Kousaka, K. Ono. Plasma Sources Sci. Technol. 12, 273 (2003).

27. R. W. Humble, G. N. Henry, W. J. Larson. Space Propulsion Analysis and Design, McGraw-Hill, New York (1995).

28. G. P. Sutton, O. Biblarz. Rocket Propulsion Elements, $7^{\text {th }}$ ed., John Wiley, New York (2001).

29. H. R. Griem. Spectral Line Broadening by Plasmas, Academic, New York (1974). 